\title{
Probability of contraceptive continuation and its determinants
}

N.H. Mahdy and N.A. El-Zeiny ${ }^{2}$

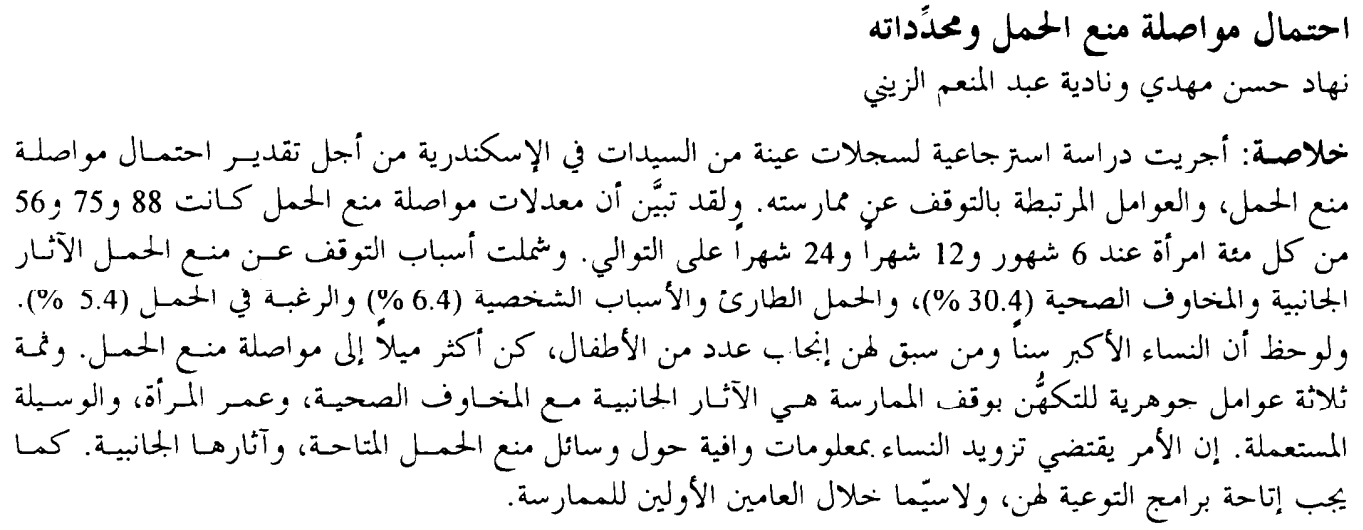

ABSTRACT Probability of contraceptive continuation and factors associated with discontinuation were assessed in a retrospective study of women's records in Alexandria. Contraceptive continuation rates were $88 / 100,75 / 100$ and $56 / 100$ women at 6,12 and 24 months respectively. Reasons for discontinuation included side-effects and health concerns $(30.4 \%)$, accidental pregnancy and personal reasons $(6.4 \%)$ and desire for pregnancy $(5.4 \%)$. Women who were older and who had several children were most likely to continue contraceptive use. Three significant predictors of discontinuation were side-effects and health concerns, age of the woman and contraceptive method. Women should be fully informed of the contraceptive methods available and their sideeffects, and counselling programmes should be offered, particularly during the first 2 years of use.

\section{Probabilité de la poursuite de la contraception et ses déterminants}

RESUME La probabilité de la poursuite de la contraception et les facteurs associés à son arrêt ont été évalués dans une étude rétrospective des dossiers médicaux de femmes à Alexandrie. Les taux de poursuite de la contraception était de 88,75 et 56 pour 100 femmes à 6,12 et 24 mois respectivement. Les raisons d'abandon comprenaient les effets secondaires et considérations de santé $(30,4 \%)$, une grossesse accidentelle et des raisons personnelles $(6,4 \%)$ et le désir de grossesse $(5,4 \%)$. Les femmes d'un âge plus avancé et ayant plusieurs enfants étaient celles les plus susceptibles de continuer à avoir recours à la contraception. Trois facteurs prédictifs importants de l'abandon étaient les effets secondaires et considérations pour la santé, l'âge de la femme et la méthode contraceptive. Les femmes devraient être pleinement informées au sujet des méthodes contraceptives disponibles et de leurs effets secondaires et des programmes d'orientation devraient être proposés, en particulier durant les deux premières années d'utilisation.

'Biostatistics Department, High Institute of Public Health, Alexandria University, Alexandria, Egypt. ${ }^{2}$ Community Medicine Department, Faculty of Medicine, Alexandria University, Alexandria, Egypt. Received: 15/10/98; accepted: 14/01/99 


\section{Introduction}

Improvement in the quality of contraceptive use is an important goal of Egypt's family planning programme [1]. Information on the level of current use of contraception is important for understanding the key determinants of fertility and for measuring the success of the national family planning programme [2].

Contraceptive use in Egypt doubled from $24 \%$ in 1980 to $48 \%$ in 1995 [3]. The pace of change was rapid in the $1980 \mathrm{~s}$, but virtually no change occurred in the use rate during 1991-1995. The shift towards more effective methods which was evident in the 1980 s continued during the first half of the 1990 s, although at a slower pace [3]. In Alexandria, $51.6 \%$ of married women used family planning methods in $1988,62 \%$ in 1992 and $59.8 \%$ in 1995 [3].

The rate at which users discontinue a method of contraception is one of the major indicators of quality of use [4]. Reasons for discontinuation may include contraceptive failure, dissatisfaction with the method and health concerns, as well as factors such as lack of availability and cost [5]. It has been reported that $30 \%$ of users in Egypt discontinue a method within 12 months of starting use [3]. Users in Egypt are more likely to discontinue use during the first year because they experience side-effects or have health concerns than for other reasons.

Continuation rates are reliable indicators of the overall use of a contraceptive method [0]. High rates of discontinuation are generally recognized as the major problem facing family planning programmes and there is a need to search for associated factors [7]. Better counselling in the selection of methods and follow-up may be needed [8]. Our goal was to study the probability of contraceptive continuation and to assess its determinants.

\section{Materials and methods}

\section{Study design and setting}

A retrospective study was conducted at the Safe Reproductive Health Clinic annexed to El-Shatby University Hospital. The clinic has a complete, clear and accurate recording system specially designed for the follow-up of contraceptive users. This system includes detailed records of the reasons for contraceptive discontinuation.

All women's records from 1996 to 1997 were examined. Data documented in the records included sociodemographic characteristics and medical and obstetric histories of attendees. Contraceptive history, including data on previously used contraceptive methods, was thoroughly reviewed. Moreover, all data about the last contraceptive method used were fully evaluated. These data included type of method [intrauterine contraceptive device (IUD), pills, injectables or Norplant], duration of use and reasons for discontinuation. Reasons for discontinuation werc cxamincd and classified into categories such as desire to become pregnant, side-effects and health concerns, and other reasons (accidental pregnancy or personal reasons, such as dissatisfaction with the method).

Incomplete records, i.e. records lacking follow-up data, were not included in the study. The percentage of women continuing use of a contraceptive method divided by duration of use was calculated to give continuation rates. Only 607 records met the criteria necessary for calculating continuation rates of the various contraceptive mcthods.

\section{Statistical analysis}

Data were analysed using SPPS (version 6). The $\chi^{2}$ test of independence was used to assess differences in characteristics of contraceptive users. Cramer's V(V) was used to 
measure strength of association [9]. Analysis of variance (ANOVA) with subsequent post hoc multiple comparison (Scheffe's technique) was used to assess differences in the means for quantitative variables [10].

The life table method was used for calculation of 2-year continuation rates [11]. Continuation rates were also estimated using Kaplan-Meier analysis and the rates of different groups were compared with a logrank test [12]. Wilcoxan-Gehan statistics was used to test differences between cumulative life table rates of the different groups. A mathematical expression involving rank was calculated and the data in a table were arranged with one group across the top and the other down the side [13].

$V^{*}=V / \mathrm{SD}(\mathrm{V})$

where: $V$ is the sum of the columns.

$\mathrm{SD}(\mathrm{V})=\sqrt{n_{1} n_{2}} \sum d^{2} / \sqrt{\left(n_{1}+n_{2}\right)\left(n_{1}+n_{2}-1\right)}$

where: $n_{1}$ and $n_{2}$ were sample sizes and $d$ is the difference in ranks.

The function followed an approximately normal distribution and thus the $Z$ distribution could be used to determine statistical significance.

The Cox proportional hazard model was used to calculate a hazard ratio for each variable adjusted for all other variables included in the model. Explanatory variables were identified using a stepwise forward procedure $[13,14]$. The Cox regression model was:

$$
h(\mathrm{t})=h_{0}(\mathrm{t}) \times \exp \left(\mathrm{B}_{1} X_{1}+\mathrm{B}_{2} X_{2}+\ldots+\mathrm{B}_{\mathrm{p}} X_{\mathrm{p}}\right)
$$

where: $B_{1}-B_{p}$ are regression coefficients; $X_{1}-X_{\mathrm{p}}$ are independent variables; and exp is the exponential function.

Where $h_{0}(\mathrm{t})$ corresponded to the hazard when all the variables were zero, it was designated as the hazard function. Independent variables included: age in years $\left(X_{1}\right)$, education $\left(X_{2}\right)$, number of living children $\left(X_{3}\right)$, contraception method $\left(X_{4}\right)$, planned pregnancy $\left(X_{5}\right)$, side-effects $\left(X_{6}\right)$, and other reasons $\left(X_{7}\right)$. All significance probabilities were calculated using two-tailed analysis.

\section{Results}

\section{Background characteristics of the women}

The total sample amounted to 607 women. The mean age of the women was $32.56+$ 6.1 years and slightly more than half $(52.6 \%)$ were educated. The majority of the uscrs $(89.0 \%)$ wcrc not employed outside the home. Mean parity was $3.92 \pm 1.92$, with an average number of $3.67 \pm 1.64$ living offspring.

IUD was the most popular method of contraception and was used by $42 \%$ of the women. Other methods used were injectables $(21.9 \%)$, pills $(18.9 \%)$ and Norplant $(17.1 \%)$. There were significant differences between the mean ages of users of the various contraceptive methods $(F=9.18, P<$ $0.001)$. The mean age was highest among users of injectables (34.20 \pm 6.16 years), followed by users of Norplant $(33.58 \pm 5.71$ years $)$ and pills $(33.0 \pm 5.56$ years $)$. The lowest age was found for IUD users (31.13 \pm 6.17 years). This was statistically significant when compared with users of Norplant and injectables (Scheffe's technique).

Contraceptive methods were not significantly related to the level of education. Mean parity was highest among users of injectables $(4.54 \pm 1.98)$, followed by users of pills $(4.37 \pm 2.24)$ and Norplant $(3.83 \pm$ $1.54)$; the difference was statistically significant $(F=13.16, P<0.001)$. The lowest mean parity was for IUD users $(3.43 \pm$ 1.72); Scheffe's technique showed a statistically significant difference when compared 


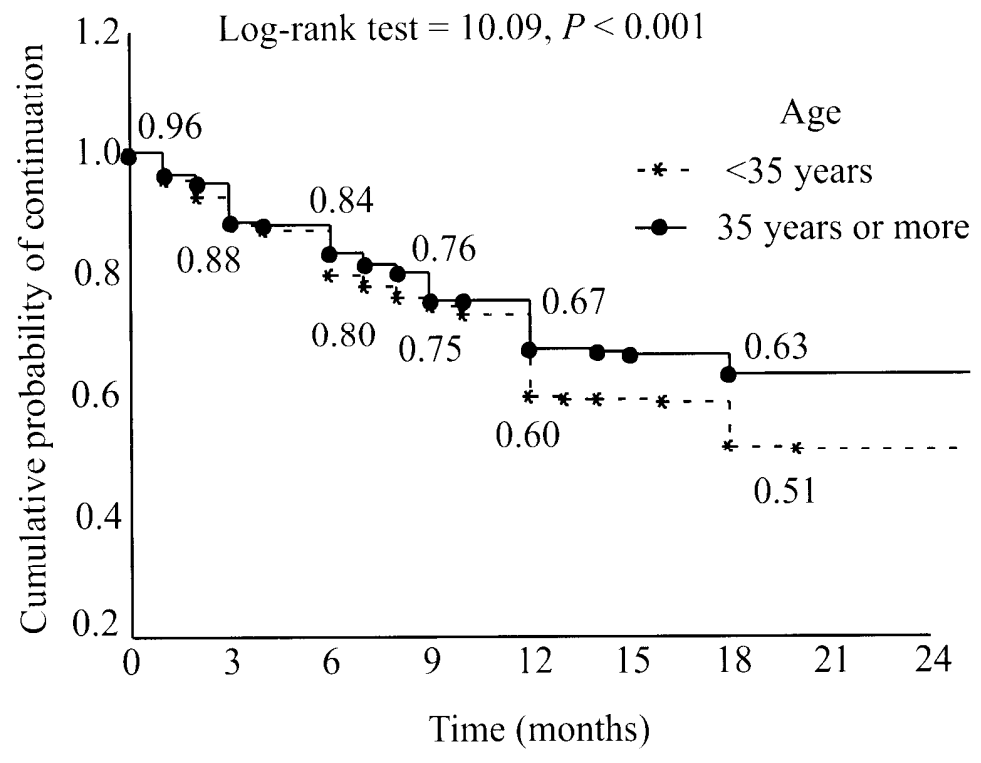

Figure 1 Cumulative contraception continuation rate of the women according to age (Kaplan-Meier technique)

with users of pills and injectables. The level of continued use among women who were not employed was higher than among working women but the difference was not significant $(P>0.05)$. The average number of living children varied significantly with the method used $(F=11.87, P<0.001)$, being lowest for IUD users $(3.25 \pm 1.55)$. Scheffe's technique showed a significant difference compared with users of pills $(3.97 \pm$ $1.75)$ and injectables $(4.18 \pm 1.63)$.

Contraceptive use increased with the number of living children and peaked at $48.6 \%$ among women with three or four children and declined to $26.7 \%$ among women with five or more children. The majority of users $(91.9 \%)$ had no history of discontinuation of the same method. However, the highest rate of previous discontinuation was noted among IUD users $(17.6 \%)$. This was statistically significant $\left(\chi_{3}^{2}=54.41, P<0.001, V=0.30\right)$.

\section{Contraceptive continuation and its} determinants

The life table technique for all methods showed that 74 of the women discontinued use within the first 6 months, resulting in a life table continuation rate of $88.0 / 100$ women; 1 - and 2-year continuation rates were $75.0 \%$ and $56.0 \%$ respectively.

According to Kaplan-Meier analysis, age was associated with the risk of discontinuation of a contraceptive method during the study period (log-rank test $=10.09$, $P<0.001)$. From $12-15$ months of use, the cumulative proportion of continuation was $67.0 \%$ for women aged 35 years or more as compared with $60.0 \%$ among those aged $<35$ years. Older women had higher continuation rates than younger ones throughout the 2 -ycar period. This was evident from 1 year of use onward. The 2-year cumulative continuation rates were $63.0 \%$ and $51.0 \%$ for older and younger women respectively (Figure 1). 


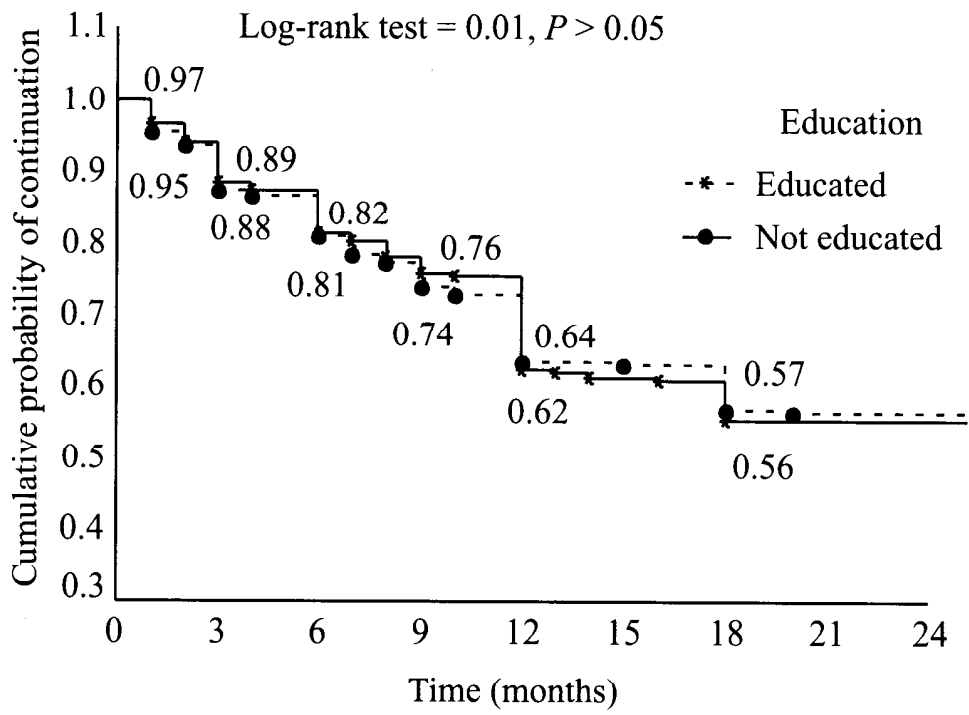

Figure 2 Cumulative contraception continuation rate of the women according to education (Kaplan-Meier technique)

Contraceptive continuation rates were not significantly associated with level of education. The 2-year continuation rates were $57.0 \%$ and $56.0 \%$ among the educated and uneducated women respectively $(P>$ 0.05 ) (Figure 2).

Women with three or four children had slightly higher continuation rates for the study years than those who had five or more children or those with one or two children (Figure 3). The 2-year cumulative continuation rate of the women with three or four children was also slightly higher: $58 \%$ compared with $56 \%$ and $53 \%$ respectively. However, these differences were not statistically significant $(\log$-rank test $=2.91, P>$ 0.05 ).

Kaplan-Meier analysis revealed a statistically significant difference in the cumulative continuation rates between the four methods of contraception (log-rank test $=$ $54.59, P<0.001$ ) (Figure 4). Six months after the start of contraception, the cumula- tive probabilities of continuation were $93.0 \%$ and $89.0 \%$ for Norplant and IUD users respectively and $68.0 \%$ for both users of injectables and pills. After 1 year of use, the cumulative continuation rate was $79.0 \%$ for Norplant, $72.0 \%$ for IUD, $52.0 \%$ for pills and $43.0 \%$ for injectables. A higher cumulative continuation rate was noted among Norplant users throughout the study period. The 2-year continuation rates were $69.0 \%$, $63.0 \%, 49.0 \%$ and $40.0 \%$ among Norplant, IUD, pills and injectables users respectively.

\section{Reasons for discontinuation}

Out of the 607 women, 351 (57.8\%) continued using contraceptive methods up to 2 years. However, 256 of those who accepted contraceptives $(42.2 \%)$ terminated use for various reasons. The most common reason for discontinuation was side-effects and health concerns $(30.4 \%)$, followed by other reasons $(6.4 \%)$, including accidental preg- 


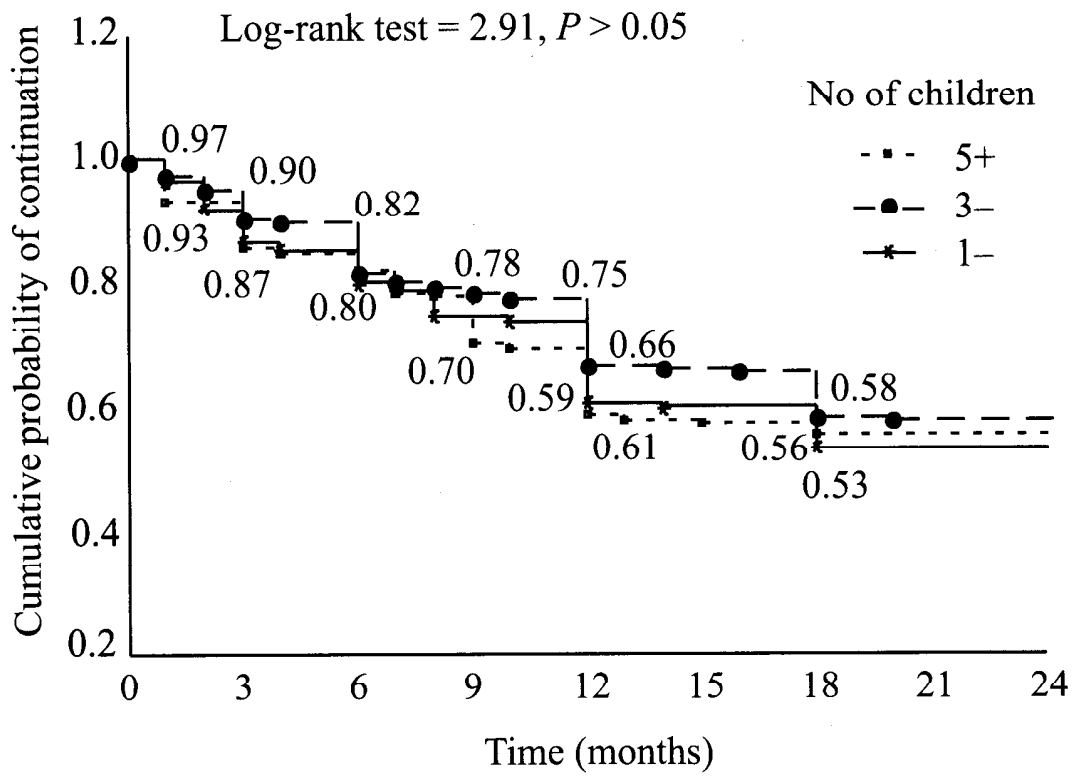

Figure 3 Cumulative contraception continuation rate of the women according to the number of children (Kaplan-Meier technique )

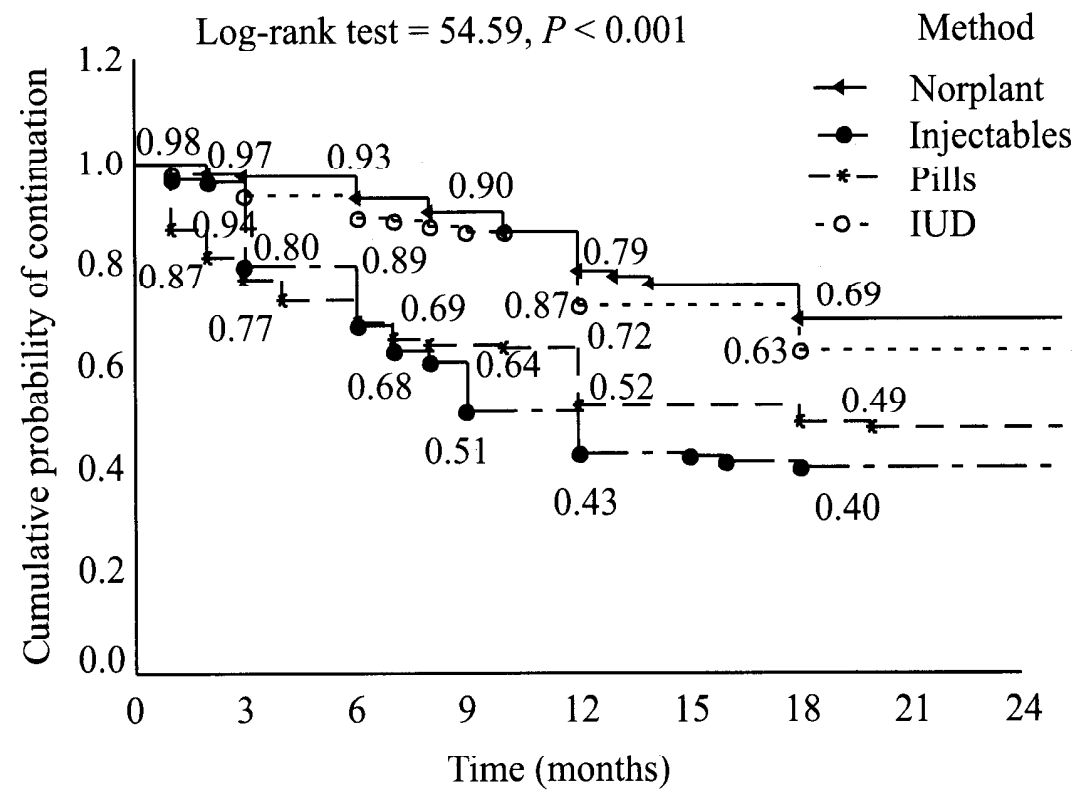

Figure 4 Cumulative contraception continuation rate of the women according to the contraceptive method (Kaplan-Meier technique) 


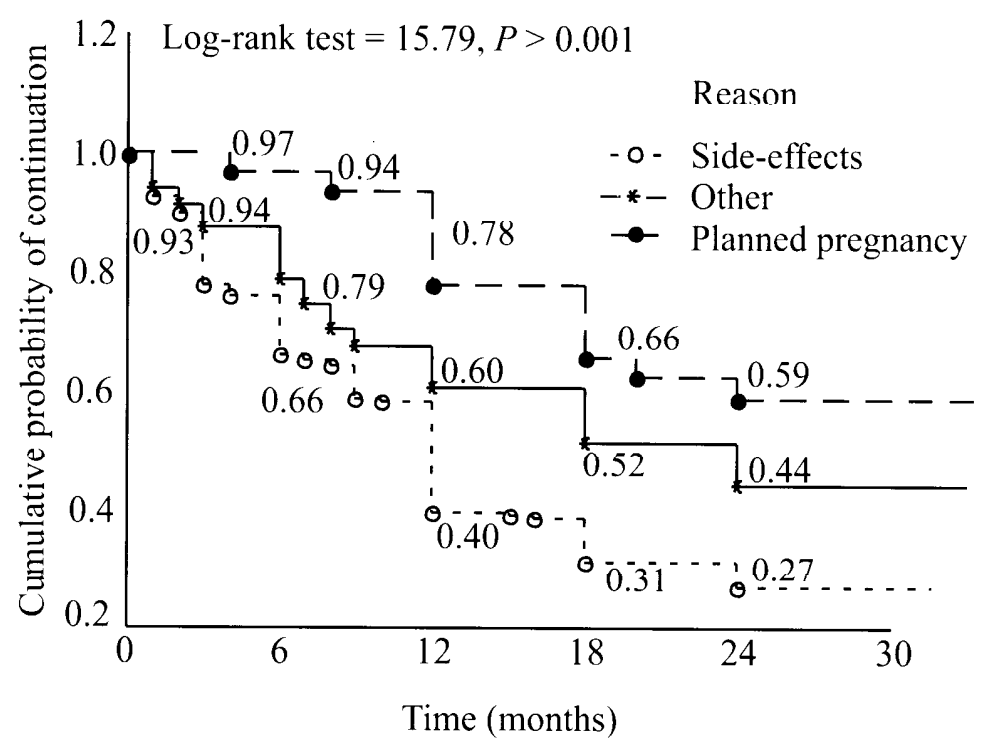

Figure 5 Cumulative contraception continuation rate of the women according to the reason for discontinuation (Kaplan-Meier technique )

nancy (10 IUD users), and the desire for pregnancy $(5.1 \%)$. When the type of the method was considered, nearly equal percentages of both IUD and pill users $(7.5 \%$ and $7.0 \%$ ) stopped use for pregnancy planning. Among injectables users, this reason was not given.

Side-effects and health concerns was the leading cause of discontinuation among pill users $(66.1 \%)$. The most common complaints were nausea $(25.2 \%)$, headache $(15.7 \%)$, weight gain $(14.8 \%)$ and leg pain and breast fullness (5.2\% each). Nearly $61 \%$ of injectable users reported side-effects; more than one-third of them complained of amenorrhoca (34.6\%) and 26.3\% had bleeding problems. About $39 \%$ of the women had Norplant implants removed because of health problems. Amenorrhoea was the most commonly reported complaint $(21.0 \%)$, followed by bleeding problems $(18.0 \%)$. Among IUD users, $36.5 \%$ re- quested remoral of the device because of side-cffects. The greatest proportion of them did so because of bleeding problems $(23.9 \%)$ and $12.6 \%$ complained of pelvic infections. Discontinuation for other reasons (personal reasons or switching to another method) was highest among pill users $(8.7 \%)$, followed by IUD users.

The overall continuation rates were generally low for those who gave side-effects as a reason for discontinuation. The $2-y e a r$ cumulative continuation rates were $66.0 \%$, $52.0 \%$ and $31.0 \%$ for other reasons, planning for pregnancy and side-effects respectively. These differences were statistically significant (log-rank test $-15.79, P<$ 0.001 ) (Figure 5).

Table 1 presents the life table continuation rate of contraceptive methods by reason for discontinuation. The overall 2-year cumulative continuation rates among women desiring pregnancy was $74 \%$ among 
Table 1 Two-year life table continuation rate of contraceptives by reason for discontinuation

\begin{tabular}{lcccccc}
\hline Reason & IUD & $\begin{array}{c}\text { Cumulative continuation rate (SE) } \\
\text { Pills }\end{array}$ & Injectables & Norplant & Overall \\
Gehan statistics
\end{tabular}

Other reasons

(ordinal months)

$\begin{array}{llllll}0- & 1.00(0.02) & 0.83(0.08) & 0.83(0.09) & 1.00(0.00) & \\ 6- & 0.86(0.05) & 0.70(0.10) & 0.55(0.12) & 1.00(0.00) & \\ 12- & 0.80(0.06) & 0.65(0.10) & 0.49(0.12) & 1.00(0.00) & 5.48 \\ 18- & 0.74(0.07) & 0.61(0.10) & 0.49(0.12) & 0.78(0.20) & \\ 24+ & 0.48(0.09) & 0.46(0.12) & 0.29(0.13) & 0.78(0.20) & \end{array}$

${ }^{a}$ compares IUDs with pills $\quad{ }^{b}$ Compares pills with injectables ${ }^{a}$ Compares IUDs with iniectables $\quad{ }^{e}$ compares pills with Norplant IUD = intrauterine device $\quad S E=$ standard error
${ }^{c}$ compares injectables with Norplant ${ }^{t}$ compares IUDs with Norplant 
Table 2 Stepwise Cox proportional hazard analysis of factors affecting 2-year contraceptive continuation rate

\begin{tabular}{|c|c|c|c|c|c|c|c|}
\hline Covariate & B & SE & $\begin{array}{l}\text { Wald } \\
\text { test }\end{array}$ & P-value & $\begin{array}{l}\text { Hazard } \\
\text { ratio }\end{array}$ & $95 \% \mathrm{Cl}$ & Model $\chi^{2}$ \\
\hline \multicolumn{8}{|l|}{ All methods } \\
\hline \multicolumn{8}{|l|}{ Side-effects and } \\
\hline health concerns $\left(X_{\theta}\right)$ & 0.9703 & 0.1121 & 74.9580 & 0.0000 & 2.64 & $2.11-3.29$ & \\
\hline Age $\left(X_{1}\right)$ & 0.3775 & 0.1129 & 11.1792 & 0.0008 & 1.46 & $1.17-1.82$ & \\
\hline Type of method $\left(X_{4}\right)$ & & & 47.5967 & 0.0000 & & & \\
\hline IUD & 0.1961 & 0.1658 & 1.3944 & 0.2368 & 1.22 & $0.87-1.68$ & \multirow[t]{3}{*}{$\chi_{5}^{2}=139.64$} \\
\hline Pills & 0.6874 & 0.1869 & 13.5248 & 0.0002 & 1.99 & $1.38-2.87$ & \\
\hline Injectables & 0.9557 & 0.1691 & 31.9417 & 0.0000 & 2.60 & $1.87-3.62$ & \\
\hline \multicolumn{8}{|l|}{ IUD } \\
\hline Other reasons $\left(X_{7}\right)$ & 0.7224 & 0.3743 & 3.7250 & 0.0536 & 2.05 & $0.99-4.29$ & \\
\hline \multicolumn{8}{|l|}{ Side-effects and } \\
\hline health concerns $\left(X_{\circ}\right)$ & 1.5755 & 0.2391 & 43.4040 & 0.0000 & 4.83 & $3.02-7.72$ & $\chi_{2}^{2}=53.51^{\mathrm{a}}$ \\
\hline \multicolumn{8}{|c|}{ Pills } \\
\hline $\begin{array}{l}\text { Planned pregnancy }\left(X_{5}\right) \\
\text { Side-effects and }\end{array}$ & 1.0440 & 0.5327 & 3.8419 & 0.0500 & 2.84 & $1.00-8.07$ & \\
\hline health concerns $\left(X_{6}\right)$ & 1.7958 & 0.3310 & 29.4427 & 0.0000 & 6.02 & $3.15-11.52$ & $\chi_{2}^{2}=37.41^{\mathrm{a}}$ \\
\hline \multicolumn{8}{|l|}{ Injectables } \\
\hline \multicolumn{7}{|l|}{ Side-effects and } & $\chi_{1}^{2}=18.92^{a}$ \\
\hline \multicolumn{8}{|l|}{ Norplant } \\
\hline Age $\left(X_{1}\right)$ & 0.5512 & 0.2739 & 4.0505 & 0.0442 & 1.74 & $1.01-2.97$ & $\chi_{1}^{2}=4.15^{\mathrm{b}}$ \\
\hline
\end{tabular}

IUD users, $38 \%$ among pills users and $20 \%$ among Norplant users (Wilcoxon-Gehan statistics $=7.66, P<0.05$ ). Among women citing side-effects and health concerns, Norplant users had the highest 2-year continuation rate $(72.0 \%)$, followed by IUD users $(37.0 \%)$ and injectables users $(23.0 \%)$. The lowest continuation rate was among pills users (19.0\%).

There was a statistically significant difference in the continuation rates as per method (Gehan statistics $=52.56, P<$ 0.01 ). Paired comparisons demonstrated a statistically significant difference between IUD users, and pills users and injectables users $($ Gehan statistics $=17.53$ and 12.91 respectively, $P<0.01$ ), and between IUD users and Norplant users (Gehan statistics = 4.77, $P<0.05$ ). A statistically significant difference was also found between Norplant users, and users of injectables and pills (Gehan statistics $=14.85$ and 12.75 respectively, $P<0.01)$. A non-significant difference was observed between pills and injectables users $(P>0.05)$.

Norplant users also had the highest 2year cumulative continuation rate for other reasons $(78.0 \%)$, followed by $74.0 \%$ among IUD users and $61.0 \%$ among pills users. The lowest continuation rate was 
among injectables users $(49.0 \%)$ but these differences were not statistically significant $(P>0.05)$.

Among women who discontinued, the last method prescribed by physicians or preferred by the users was Norplant $(40.1 \%)$ and IUD (30.8\%). Pills or injectables were prescribed to only $4.5 \%$ of the women, sterilization was preferred by $3.2 \%$ and $16.9 \%$ indicated no further need of contraception.

\section{Factors predicting 2-year continuation rates}

Table 2 summarizes the results of Cox regression analysis for covariates predicting 2 years of contraceptive continuation. Of the seven variables studied, only three were significantly associated with hazard of discontinuation. The most significant factor was side-effects and health concerns; women who cited this reason had a hazard ratio for discontinuation approximately three times that of those free from complaints. The second most significant factor was age. Women aged $<35$ years had a hazard ratio of 1.46 relative to those aged 35 years or more. Type of method was the third most significant factor influencing rate of continuation. Pills and injectables users had hazard ratios of 1.99 and 2.60 respectively relative to Norplant users; IUD users had slight but nonapparent hazard relative to Norplant users $\left(\chi_{5}^{2}=139.64, P<0.001\right)$.

Among IUD users, other reasons (personal reasons or accidental pregnancy) was a significant predictor of discontinuation (hazard ratio $=2.05,95 \%$ confidence interval 0.99-4.29), followed by side-effects and health concerns (hazard ratio $=4.83,95 \%$ confidence interval 3.02-7.72). Among pill users, planned pregnancy was the predominant predictor of discontinuation (hazard ratio $=2.84,95 \%$ confidence interval
1.00-8.07), followed by side-effects. Those who complained of side-effects had about six times the hazard of discontinuation relative to those free from problems. Among injectable users, side-effects were the only significant factor for discontinuation (hazard ratio $=2.50,95 \%$ confidence interval 1.64-3.82). Among Norplant users, age was significantly associated with risk of discontinuation. Those aged $<35$ years had approximately two times the hazard of discontinuation relative to those aged $>35$ years $\left(\chi_{1}^{2}=4.15, P<0.05\right)$.

\section{Discussion}

IUD was the most popular contraceptive method used by the women $(42 \%)$, followed by hormonal methods $(21.9 \%, 18.9 \%$ and $17 \%$ for injectables, pills and Norplant respectively). Reports from the Egypt Demographic and Health Survey 1995 (EDHS) revealed that IUD use rose from $28 \%$ of married women in 1992 to $30 \%$ in 1995 [3]. There was also a small increase from $0.5 \%$ to $2.4 \%$ in the use of injectables between 1992 and 1995. Pill use continued to decline from $13 \%$ in 1992 to $10 \%$ in 1995 . The high rate of IUD use has been attributed to its qualities as a safe, cffective, incxpensive and long-acting method, which is independent of coitus $[15,16]$. In contrast, however, the popularity of IUDs among women of reproductive age in Europe varies from $5 \%$ in Great Britain to $19 \%$ in France and $21 \%$ in Finland $[15,10]$.

Current use of contraceptives was associated with a woman's age. The mean age of users was $32.56 \pm 6.10$ years. The use of hormonal contraceptive methods was significantly associated with a higher mean age and also with higher parity and number of children. EDHS revealed that the use of

المجلة الصحية لشرق المتوسط، منظمة الصحة العالمية، المجلد الخامس، العدد ب ، 1999 
injectables peaked among users aged 30-44 years [3]. Women of these ages had usually completed their familics and hence they wanted more effective methods of contraception. Injectable contraceptives have several advantages: they are simple to administer, require minimum patient compliance with an administration schedule and reduce user error. In addition, they are independent of coitus, cannot be detected, do not interfere with lactation and are highly effective $[5,6,17]$.

Previous studies have found that the use of contraceptives increases directly with a woman's level of education and her work status [18]. However, we did not find a significant relationship betwecn contraccptive use and the women's education or occupation.

The continuation rate of various contraceptive methods was $75 \%$ at 1 year and declined to $56.0 \%$ at 2 years in our study. Higher rates of continuation were found for Norplant (79.0\% and $69.0 \%$ at 1 year and 2 years respectively). In Taiwan, the continuation rate of Norplant was $90.0 \%, 78.0 \%$, $70.0 \%, 61.0 \%$ and $42.0 \%$ for $1,2,3,4$ and 5 years after insertion respectively [19]. In Singapore, the continuation rate of Norplant after 5 years was $60 \%$. This is comparable to the continuation rates mentioned in other studies $[20,21]$.

Age of user was significantly associated with the risk of discontinuation of a contraceptive method. The risk of discontinuation was highest among those aged $<35$ years. Higher 2-year cumulative continuation rates were observed among women who had either three to four or five or more children. Walther Meade et al. found that women with more living children were more likely to continue using injectables [22]. Women with only one child had the highest discontinuation rates: $74.9 / 100$ at 12 months and
$83.3 / 100$ at 18 months. Women with two or three children had lower discontinuation ratcs (59.9/100 at 12 months and 68.7/100 at 18 months). Women with four or more had similar rates $(53.5 / 100$ at 12 months and $65.7 / 100$ at 18 months) [22].

We found that after 1 year of use, the cumulative continuation rates for users of IUD and pills were $72.0 \%$ and $52.0 \%$ respectively and declined to $63.0 \%$ and $49.0 \%$ at 2 years for the two methods respectively. Anderson et al. cited that the continuation rate at 5 years was $44.5 \%$ for Nova $T$ and was higher in older age groups [16]. EDHS revealed that the 1 -year discontinuation rate was $46.0 \%$ for pill users. The IUD had the lowest rate with only $14.0 \%$ of IUD users discontinuing use during the first 12 months [3].

Among injectables users, we found that cumulative continuation rates were $43.0 /$ 100 and 40.0/100 women at 1 year and 2 years respectirely. O'Dell et al. in their study of continuation rates among postpartum adolescents in USA reported that the continuation rates at 12 months were similar for both users of pills and injectables (34.0\% and $32.0 \%$ respectively) [23] Davidson et al. found that the majority of women discontinued use of depot medroxyprogesterone acetate (DMPA) within the first year. The cumulative life table discontinuation rate at 12 months was $58 \%$ and discontinuation tended to occur very rapidly with orer half $(51 \%)$ of all discontinuers, or $31 \%$ of the sample, stopping after the first injection. An additional $18 \%$ of discontinuers stopped after the second injection [2t]. Alihonou et al. reported in their study in Benin, West Africa that 1 year after the start of contraception, the cumulative proportion of discontinuation was $59.2 \%$ for oral contraceptives, $48.1 \%$ for injection and $5 \%$ for IUD [25]. 
Results of our study revealed that sideeffects and health concerns $(30.4 \%)$ were the most common reason for discontinuation of contraceptive methods. A minority of women $(5.4 \%)$ discontinued use because they wanted another pregnancy. Other reasons accounted for $6.4 \%$ of all reasons for discontinuation. EDHS found that $12 \%$ of all users reported stopping use because of side-effects and health concerns. $4.0 \%$ stopped because they wanted to become pregnant and $10.0 \%$ stopped for other reasons [3].

Rates of discontinuation varied with method. About $30 \%$ of users mentioned side-effects and health concerns as the reason for discontinuation. The 2-year discontinuation rate due to side-effects or health concerns was highest among pills users $(81 \%)$, followed by injectables users $(77.0 \%)$, IUD users $(63.0 \%)$ and Norplant users $(2.8 .0 \%)$ A study in India reported that the discontinuation rates for Norplant at 1 year and 2 years were $43.0 \%$ and $22.0 \%$ respectively because of menstrual problems, side-effects and medical reasons. Most of the discontinuations as a result of menstrual problems occurred in the second year of the study and then decreased stcadily thereafter [2].

Sivin et al. reported that one of the drawbacks of IUD use was the increase in menstrual bleeding leading to discontinuation of the method by $5 \%-15 \%$ of users in the first year [26]. The most common personal reasons for discontinuation of IUD were planned pregnancy $(32.0 \%)$ and husband and family opinion against IUD use $(26.0 \%)$. The gross cumulative 12 -month life table discontinuation rate for all personal reasons was $41 / 100$ women [26].

Paul et al. reported that $53.0 \%$ of women used injectables for a total of 12 months or more [5]. Side-effects were given as the most common reason for stopping, with menstrual disturbances and weight gain being frequently cited. Other reasons for stopping included no further need for contraception and doubts about the appropriateness of injectables [5]. Davidson et al. in the USA reported that three-quarters of users cited either menstrual side-effects $(36.0 \%)$, such as amenorrhoea or irregular blceding. or other side-effects $(39.0 \%)$, such as weight gain, headache. mood changes or acne as the primary reasons for discontinuation of DMPA [2f]. Meade et al. rcported that the life table discontinuation rate was 57/100 women at 12 months and $69.0 \%$ at 18 months. The single most common reason for discontinuation was amenorrhoea followed by blecding problems [22]. A comparative multicentre clinical trial of oral contraceptives was conducted in Malarsia, Egypt. Thailand and Mexico and revealed that 11 -month discontinuation rates were 28.8/100 women [27]. Discontinuation rates due to menstrual problems, side-effects and other medical reasons were $7.1 \%, 5.1 \%$ and $3.8 \%$ respectively [27].

Cox proportional hazards defined three factors affecting continuation rates: side-effects and health concerns: age (women aged $<35$ years had a hazard of 1.46 relative to those aged 35 years or more): and type of method (pills and injectables had hazard ratios of 1.99 and 2.60 respectively relative to Norplant). Among IUD users, other reasons emerged as significant predictors of discontinuation (hazard ratio $=2.05$ ), followed by side-effects and health concerns (hazard ratio $=4.83$ ). Petta et al. in their analysis of personal reasons for discontinuation of IID use reported that lack of education and living in a rural area were significant factors associated with discontinuation. No risk factors were defined for discontinuation due to planned pregnancy [2]. 


\section{Recommendations}

Prospective uscrs should reccive complete information about possible changes in menstrual patterns and other health concerns associated with various contraceptive methods. For the dissemination of this in- formation, counselling programmes are needed prior to and during use. Further large-scale investigations throughout all governorates of Egypt are needed to define the underlying causes of discontinuation of various contraceptive methods.

\section{References}

1. Lahteenmaki $P$ et al. Selection and performance of the levonorgestrel-releasing intrauterine system. Acta obstetricia et gynecologica Scandinavica supplement, 1997, 164:69-74.

2. Petta $C A$ et al. An analysis of the personal reasons for discontinuing IUD use. Contraception, 1994, 50:339-47.

3. National Population Council, Cairo, Egypt. Egypt demographic and health survey 1995. Colverton, Maryland, Macrointernational Incorporated, 1996.

4. Singh $\mathrm{K}$ et al. Acceptability of Norplant implants for fertility regulation in Singapore. Contraception, 1992, 45(1):39-47.

5. Paul C, Skegg D, Williams S. Depot medroxyprogesterone acetate. Patterns of use and reasons for discontinuation. Contraception, 1997, 56:209-14.

6. Sangi-Haghpeykar $\mathrm{H}$ et al. Experiences of injectable contraceptive users in an urban setting. Obstetrics and gynecology, 1996, 88:227-33.

7. Gardy WR et al. Contraceptive failure and continuation among women in the United States, 1970-5. Studies in family planning, 1993, 14(1):9-19.

8. Ferguson AC. Fertility and contraceptive adoption and discontinuation in rural Kenya. Studies in family planning, 1992, 23:257-67.
9. Healey JF. Statistics: a tool for social research, 2nd ed. California, Wadsworth Publishing Company, 1990:268-9.

10. Sachs L. Applied statistics: a handbook of techniques. New York, SpringerVerlag, 1982:502-7.

11. Jejeebhoy $S$. Measuring the quality and duration of contraceptive use: an overview of new appraoches. Population bulletin of the United Nations, 1989, 26:22-33.

12. Armitage P, Berry G. Statistical methods in medical research, 2nd ed. London, Blackwell Scientific Publications, 1991:428-30.

13. Dawson-Saunders B, Trapp RG. Basic and clinical biostatistics. New Jersey, Prentice Hall Incorporated, 1990:196-9.

14. Altman DG. Practical statistics for medical research. London, Chapman and Hall, 1991:387-93.

15. Diaz $\mathrm{J}$ et al. Performance of the copper T200 in parous adolescents: are copper IUDs suitable for these women? Contraception, 1993, 48:23-7.

16. Andersson K, Odind V, Rybo G. Levonorgestrel-releasing and copper-releasing (Nova T) IUDs during five years of use: a randomized comparative trial. Contraception, 1994, 49:56-72. 
17. Oddens BJ et al. Contraceptive use and attitudes in Great Britain. Contraception, 1994, 49:73-83.

18. Chumnijarakij T et al. Study on the factors associated with contraceptive discontinuation in Bangkok. Contraception, 1984, 29(3):241-9.

19. Tseng LH et al. Norplant subdermal contraceptive system: experience in Taiwan. Contraception, 1996, 53:117-80.

20. Singh $\mathrm{K}$ et al. Acceptability of Norplant implants for fertility regulation in Singapore. Contraception, 1992, 45(1):39-47.

21. Grubb GS, Moore D, Anderson G. Preintroductory clinical trials of Norplant implants: a comparison of seventeen countries experience. Contraception, 1995, 52:287-96.

22. Walther Meade $C$ et al. A clinical study of orethisterone enanthate in rural Mexico. Studies in family planning, 1984, 15(3):143-8.
23. O'Dell CM et al. Depot medroxyprogesterone acetate or oral contraception in postpartum adolescents. Obstetrics and gynecology, 1998, 91(4):609-14.

24. Davidson AR et al. Injectable contraceptive discontinuation and subsequent unintended pregnancy among low-income women. American journal of public health, 1997, 87(9):1532-5.

25. Alihonou $E$ ot al. Contraceptive continuation and its determinants in Benin. Contraception, 1997, 55:97-101.

26. Sivin I et al. Four-year experience in a randomized study of the Gyne T 380 Slimline and the Standard Gyne T 380 intrauterine copper devices. Contraception, 1993, 47(1):37-42.

27. Dunson TR et al. A comparative study of two low-dose combined oral contraceptives: results from a multicenter trial. Contraception, 1993, 48:109-19. 